\title{
THE ECOLOGICAL GENETICS OF THE SPECKLED WOOD BUTTERFLY, PARARGE AEGERIA L.-A PRELIMINARY STUDY
}

\author{
LAURENCE PACKER \\ Ramsay Wright Department of Zoology, University of Toronto, 25 Harbord Street, Toronto, \\ M5S 1A1, Ontario, Canada
}

Received 3.viii.83

\section{SUMMARY}

Phenologic and geographic variation in background colouration and hind wing spotting in the Satyrid butterfly Pararge aegeria are described from a study of cabinet specimens. This species has two generations in the year. The spring generation exhibits a bimodal pattern of emergence: those individuals which overwinter as pupae emerging earlier than those which pass the winter in the larval state. These early and late spring broods exhibit statistical phenotypic differences which seem to become obscured in the summer generation. Butterflies from Ireland and the South-West Peninsula are statistically distinct from those in the rest of Great Britain. A comparison between the ecological genetics of this species and Maniola jurtina is made.

\section{INTRODUCTION}

Spotting patterns on the wings of Satyrid butterflies are excellent examples of quantitative characters which are under polygenic control. They provide suitable material for the study of natural selection in operation. Hitherto, Maniola jurtina (L.) has been the only species studied in detail (Ford, 1975). The aim of this paper is to show the results of a preliminary investigation of the ecological genetics of another Satyrid, the Speckled Wood butterfly Pararge aegeria $\mathrm{L}$, based upon an analysis of cabinet specimens. This species seemed worthy of investigation because it provides us with a more complex situation than is the case with $M$. jurtina, for the following reasons-(i) it shows variation in the spotting on the under and upper side of the hind wings and also in its background colouration; (ii) it is unique amongst British butterflies in that it overwinters in both larval and pupal stages in the same locality, thus giving rise to a two-phase spring emergence with phenotypic differences between the early and late emerging forms (Ford, 1962) and (iii) $P$. aegeria has two generations in the year whereas $M$. jurtina is univoltine.

\section{LIFE HISTORY AND VARIATION}

$P$. aegeria frequents clearings and pathways in woodland areas where suitable foodplants such as cocks foot-Dactylis glomerata and couch grass Agropyron repens are to be found. It is widely distributed throughout the British Isles but is absent from the extreme North of England and the South of Scotland, thus the Central and Northern Scottish populations are isolated from the more Southern ones. It is also absent from the extreme East of England and the Isle of Man (Skelton and Heath, 1975; Ford, pers. comm.). 

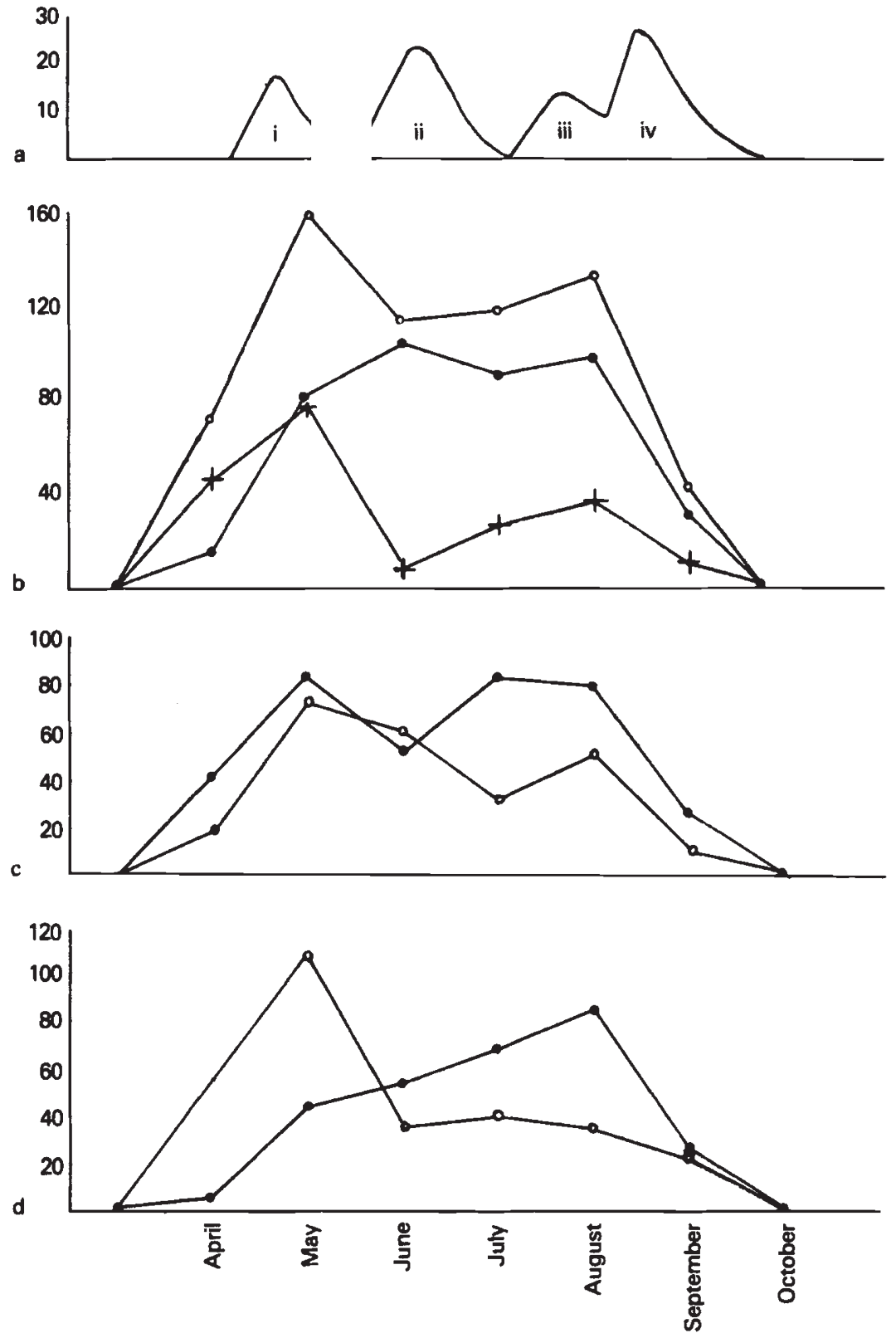

Fig. 1. (a) Phenology of a small population of Pararge aegeria. From Goddard (1967). (i) early spring brood, (ii) late spring brood, (iii) early summer brood and (iv) late summer brood. (b) Monthly variation in upper hind wing spotting and total number of individuals. Open circles, total number of butterflies. Crosses, number of butterflies with three spots. Closed circles, number of individuals with four spots. (c) Monthly variation in under hind wing spotting. Open circles, number of butterflies with five spots. Closed circles, number with six spots. (d) Monthly variation in background colouration. Open circles, number of pale individuals. Closed circles, number of dark butterflies. 
The pattern of emergence of this species has been studied by Goddard $(1962,1967)$. It has two generations in the year-a spring one which is active from April until early July, and a summer generation which is on the wing from late July until October. As can be seen (fig. 1(a)), each generation consists of two separate emergences so that early and late spring and early and late summer broods can be identified. The early spring brood is formed from individuals which overwintered as pupae and they are to be found on the wing in April and May. The late spring brood is formed from individuals which overwintered in the larval stage and these are to be found as adults in June and July. This two-phase emergence of the spring generation produces a bimodal pattern of abundance in the summer generation. Thus the early spring brood adults produce offspring which emerge in late July and the offspring of the late spring brood commence their emergence in August. The separation of broods in the summer generation is not as clear cut as it is in spring. It should be noted that Goddard studied a small population in a restricted area-in a larger population, or in a data set collected from a wide area over a longer period of time, the separation of the different broods and generations will not be as clear. Furthermore, in a larger population or over a longer time span, it is quite likely that there will be an overlap between the early and late spring broods with a possibility of interbreeding, as almost certainly occurs in the summer generation.

$P$. aegeria varies in the number of spots on the upper and underside of the hind wings and in the depth of its background colouration. The upper hind wing spots are small, black, often white pupilled and are located within the submarginal yellow patches. They vary in number from three to four, and if only three are present then it is the most anterior one which is missing. The underside hind wing spots are rings of dark brown with cream coloured centres, situated in the pale background colouration. There are usually five or six of these spots and in all but three individuals, out of over six hundred, it was the anal spot which was missing; these three specimens were treated as six spotted as they presumably had the genotype to produce the anal spot. For the same reason, the few individuals with the anal spot duplicated, giving a total of 7 spots, were included with the six spot forms in the analysis. $P$. aegeria shows considerable variation in the depth of its background colouration and in the extent to which this encroaches upon the yellow patches, the paler individuals having larger yellow markings which enhance the effect of the pale colouration.

It has been suggested (Ford, 1962) that the early spring brood of $P$. aegeria may be paler and have fewer upper and under hind wing spots than the later emerging individuals. Thus the early spring brood tends to have three upper and five under hind wing spots and is pale in background colouration whereas the late spring brood tends to have four upper and six under hind wing spots and are darker in colour.

\section{Materials AND MEthods}

Data were obtained from over six hundred specimens of $P$. aegeria, the majority of which were from collections at the British Museum and the Hope Department of Entomology at Oxford; the remainder came from private collections and specimens caught in the field in 1975. For each individual the following information was recorded-(1) Day, month and 
year of capture. Because of the tendency of collectors to take only fresh specimens the date of capture of any specimen will closely approximate to its day of emergence unless it is obviously an aged or worn individual, (2) The locality of capture, (3) The sex of the specimen, easily deduced by the lack of scent scales on the forewings of the females, (4) The number of upper hind wing spots, (5) The number of under hind wing spots, (6) Whether the specimen was of the pale or dark form-in practice this was not always easy although classification was achieved in most cases.

The three phenotypic variables were tested for sexual dimorphism and geographical and phenological variation. Sample sizes were large enough for statistical analysis of geographic variation in the following five areas-(i) the South-West peninsula: Devon and Cornwall; (ii) Central Southern England: Dorset, Somerset, Wiltshire and Hampshire; (iii) the South-East: Kent, Surrey and Sussex; (iv) the Midlands: between the above areas and the Wash and (v) Ireland. Phenotypic variation between early and late broods of both spring and summer generations was difficult to analyse because the distinction between broods was not clear from the pattern of emergence shown by these cabinet specimens (as can be seen from fig. 1(b)). Furthermore there appears to be a general shift forwards in the timing of emergence in the specimens used in this study, in comparison to those observed by Goddard. For these reasons the specimens caught in April, May, July and August were taken as being representative of the early and late spring and early and late summer broods respectively.

\section{Results}

The results for sexual dimorphism for spotting frequencies (table 1) show no significant differences between the sexes, a situation interestingly different from that found in $M$. jurtina and useful in that all further calculations involving spotting need take no account of sexual differences. Results for paleness, however, show a preponderance of pale females and dark males over the expected values. This could be due to errors of judgement because females are generally paler than males and have larger yellow markings. However, because males and females varied in a similar way in their background colouration in relation to the other variables under consideration, they are dealt with together in the following analyses.

As can be seen from table 2, there is a significant association between paleness and upper hind wing spotting and between paleness and under

TABLE 1

Spotting and background colouration frequencies in male and female $\mathrm{P}$. aegeria

\begin{tabular}{lcccc}
\hline & \multicolumn{5}{c}{ male } & female \\
\hline upper hind & 3 & 143 & 70 & $\chi^{2}=0.001$ \\
wing spotting & 4 & 265 & 129 & $p>0.95$ \\
under hind & 5 & 129 & 70 & $\chi^{2}=0.73$ \\
wing spotting & 6 & 263 & 122 & $p>0.05$ \\
background & pale & 168 & 118 & $\chi^{2}=21.78$ \\
colouration & dark & 214 & 66 & $p<0.001$ \\
\hline
\end{tabular}


TABLE 2

Table showing association of the phenotypic characteristics under investigation

\begin{tabular}{|c|c|c|c|c|c|}
\hline & & \multicolumn{2}{|c|}{ Under hind wing spots } & \multicolumn{2}{|c|}{ Background colouration } \\
\hline & & 5 & 6 & $P$ & $D$ \\
\hline $\begin{array}{l}\text { Upper hind } \\
\text { Wing spots }\end{array}$ & $\begin{array}{l}3 \\
4\end{array}$ & $\begin{array}{r}70 \\
131\end{array}$ & $\begin{array}{l}118 \\
273\end{array}$ & $\begin{array}{l}123 \\
170\end{array}$ & $\begin{array}{r}68 \\
219\end{array}$ \\
\hline Significance & & \multicolumn{2}{|c|}{$x^{2}=0.747, p>0.05$} & \multicolumn{2}{|c|}{$\chi^{2}=21.93, p<0.001$} \\
\hline $\begin{array}{l}\text { Under hind } \\
\text { Wing spots }\end{array}$ & $\begin{array}{l}5 \\
6\end{array}$ & & & $\begin{array}{l}149 \\
178\end{array}$ & $\begin{array}{r}50 \\
196\end{array}$ \\
\hline Significance & & & & \multicolumn{2}{|c|}{$\chi^{2}=39.5, p<0.001$} \\
\hline
\end{tabular}

hind wing spotting. In each case there are more individuals showing the combinations predicted for the early and late spring forms. The association between spotting on the upper and under side of the hind wings does not appear to be significant. However, if the Irish specimens are removed from the sample then this association becomes significant as shown in table 3 . The difference in significance obtained according to whether the Irish specimens are included or not is due to a paucity of five under hind wing spotted forms in the Irish sample; we shall return to this later.

TABLE 3

Association between upper and under hind wing spotting with the Irish specimens removed from the sample

\begin{tabular}{lccc}
\hline & \multicolumn{2}{c}{ under hind wing spots } \\
\cline { 2 - 4 } & & 5 & 6 \\
\hline upper hind & 3 & 67 & 121 \\
wing spots & 4 & 87 & 219 \\
Significance & & \multicolumn{2}{c}{$x^{2}=4 \cdot 54, p<0.05$} \\
\hline
\end{tabular}

Table 4 tests the null hypothesis that there is no significant difference in the relative proportions of the early and later phenotypes in the early and late spring and summer broods. As can be seen three spotted and pale forms are more abundant in the early spring brood than expected, but there is no departure from the null hypothesis for each of the three variables in summer or for under hind wing spotting in spring. Fig. 1(b, $\mathrm{c}$ and d) shows the phenological data graphically. All three characteristics show a bimodal distribution and the preponderance of three spotted and pale individuals in the early spring brood can be seen.

Statistical analysis of the three phenotypic variables from the five areas reveals that there is significant geographic variation in upper and under hind wing spotting $\left(\chi^{2}=17.45, p<0.001\right.$ and $\chi^{2}=21.65, p<0.001$ respectively). However, there is no significant variation in background colouration $\left(\chi^{2}=2.44, p>0.05\right)$. Further analysis shows that area (i) is significantly 
TABLE 4

Contingency table examining relationship between the three phenotypic variables and brood

\begin{tabular}{|c|c|c|c|c|c|}
\hline & & \multicolumn{2}{|c|}{ Spring } & \multicolumn{2}{|c|}{ Summer } \\
\hline & & April & May & July & August \\
\hline upper hind & 3 & 46 & 76 & 27 & 36 \\
\hline wing spots & 4 & 16 & 80 & 89 & 96 \\
\hline significance & & $x^{2}=11 \cdot 7$ & $p<0.005$ & $x^{2}=0.53$ & $p>0.05$ \\
\hline under hind & 5 & 20 & 73 & 33 & 51 \\
\hline wing spots & 6 & 42 & 83 & 84 & 82 \\
\hline significance & & $x^{2}=3.77$ & $p>0.05$ & $x^{2}=2 \cdot 87$ & $p>0.05$ \\
\hline background & pale & 57 & 108 & 41 & 35 \\
\hline colouration & dark & 6 & 45 & 69 & 85 \\
\hline significance & & $x^{2}=11 \cdot 0$ & $p<0.005$ & $x^{2}=1.65$ & $p>0.05$ \\
\hline
\end{tabular}

TABLE 5

A comparison of upper hind wing spot frequencies for areas $i$ and $i i$

\begin{tabular}{lccc}
\hline & & Area & Area ii \\
\hline $\begin{array}{l}\text { Number } \\
\text { of spots }\end{array}$ & 3 & 30 & 45 \\
Significance & 4 & 103 & 69 \\
\hline
\end{tabular}

TABLE 6

A comparison of under hind wing spotting for Irish and English specimens

\begin{tabular}{lccc}
\hline & & Irish & English \\
\hline under hind & 5 & 13 & 188 \\
wing spots & 6 & 85 & 306 \\
Significance & & $\chi^{2}=20 \cdot 4, p<0 \cdot 001$ \\
\hline
\end{tabular}

different with respect to upper hind wing spotting from both area (ii) and the whole of the rest of the south of England taken as a unit (table 5), and Ireland is significantly different from the mainland of Great Britain with respect to under hind wing spotting (table 6).

\section{Discussion}

Pararge aegeria is unique amongst British butterflies in that it overwinters in both the larval and pupal stages, thus giving rise to a bimodal pattern of emergence in spring. Given that even in small populations, the early and late emerging forms have a chance to interbreed, at least in the summer 
generation, how is it that the broods remain distinct? It is unlikely that genes involved in promoting the early spring phenotypes also produce a faster growth rate in the immature stages. If this were so we would expect a greater separation between the broods in summer than in spring, whereas the reverse is the case. It could be that the early spring phenotype produces a faster growth rate only under wintery conditions. However, it is more likely that intermediates between early and late forms are at a disadvantage with the onset of winter. The necessity to enter diapause confers an advantage on individuals with growth rates well timed to overwinter as pupae or larvae and is disadvantageous to those individuals with less precisely matched growth. Clearly such constraints do not apply to the offspring of the spring generation and it is likely that the early and late spring broods are kept distinct due to these diapause constraints.

Another interesting question concerns the origin of this unusual life cycle. Several species of insect exhibit a bimodal emergence of adults from pupae (Waldbauer, 1978) and in at least two cases there is evidence for a, genetic basis for this (Waldbauer and Sternberg, 1973; Bradshaw, 1973). Recently Brakefield (1982b) has reported bimodal emergence in the univoltine $M$. jurtina, a species which also shows genetic variation in larval growth-rate (Brakefield, 1982c). Presumably, bivoltinism in $\boldsymbol{P}$. aegeria evolved from an ancestral univoltine life cycle. If such an ancestor had a bimodal emergence pattern this could have been exaggerated if there were two generations in the year. Bimodality in the summer generation could result in the offspring of the late emerging individuals having insufficient time for the completion of larval growth before the arrival of winter. Thus the earlier hatching larvae could overwinter as pupae whereas the remainder would have to enter a larval diapause.

The early and late spring broods of $P$. aegeria exhibit statistical phenotypic differences: the earlier individuals are generally paler and have fewer hind wing spots than those that emerge later in the spring. The phenotypic difference between broods does not reappear in the summer generation in the data used here. However, a study of the ecological genetics of the summer generation in one locality shows significant differences between early and late summer broods in all three phenotypic variables (Packer, in preparation). The early and late spring broods overwinter as pupae and larvae respectively. They experience different environmental conditions, and therefore different selective forces. The fact that the early spring phenotype reappears in the second, summer, generation argues against the possibility that the differences between the early and late spring forms are environmentally caused. During the development of the summer generation the offspring of both spring broods are subject to similar climatic conditions and the reappearance of early spring form characteristics in the summer generation shows that this phenotype must have a strong genetic component. The fact that the second mode for the early spring phenotype is smaller than its first mode and smaller than the summer mode for the late spring form indicates that selection during the summer tends to disfavour the early spring form. It would seem that we have here an example of cyclic selection (Ford, 1975) whereby a genotype which confers a selective advantage to individuals for one or more generations subsequently becomes disadvantageous for one or more generations and this pattern of alternating advantage and disadvantage is repeated over and over again. In $P$. aegeria 
the situation is quite complex. It would appear that the pale and three upper hind wing spotted genotypes are at an advantage in individuals which overwinter as pupae and hence they preponderate in the early spring brood. However the same genotypes are at a slight disadvantage during the summer resulting in the lower summer mode for their resultant phenotypes. Thus in the earlier emerging broods there is an alternation of selective advantage and disadvantage to the pale and three spotted genotypes. But in those individuals which overwinter as larvae, the dark and four spotted genotypes appear to be at a distinct advantage during the winter and these genes appear not particularly disfavoured during the summer. Thus, cyclic selection seems to operate only on the three spotted genotype.

The gene frequency differences between early and late spring broods could be brought about by different rates of exposure to parasitism or predation in those individuals which pupate at the end of one year and those that do so at the beginning of the next. We have an example of this phenomenon in the closely related M. jurtina. Dowdeswell (1961) found that adult females bred from larvae collected in the field in May showed a much diminished frequency of spotless forms in comparison with wild caught females, but that adults bred from larvae collected in June had a similar spot pattern distribution to the wild females. He also found that the larvae collected in June had a much higher mortality rate than those collected in May (31.8 per cent compared to 10.4 per cent and 39.3 per cent compared to 19.8 per cent, in 1959 and 1960 , respectively) and that about three quarters of this mortality was a result of parasitism by the braconid wasp Apanteles tetricus. Thus it seems that the larvae destined to produce butterflies with higher spot numbers are more susceptible to braconid parasitism. It is possible that $P$. aegeria individuals which overwinter as larvae are more susceptible to the attacks of parasites than those which complete their growth and pupate before the arrival of winter. Selection as a result of such differential exposure to mortality could be responsible for the differences in spotting and background colouration between the early and late spring broods.

Phenotypic differences between generations of bivoltine butterflies are known for Araschnia levana and Cyaniris argiolaus. In the former temperature and developmental rate differences produce remarkably different spring and summer generations (Suffert, 1924). The situation in the holly blue butterfly Cyaniris argiolus is more complex, but less well known-the offspring of the two generations utilising different foodplants as well as exhibiting colouration differences (Ford, 1962).

M. jurtina exhibits distinct sexual dimorphism in ecological niche and spotting patterns (Brakefield, 1982 $a$ and $c$ ). It has been suggested that as a result of differential niche occupation, the sexes are subject to different selection pressures and that this results in the sexual dimorphism in spotting (Handford, 1973; Brakefield, $1982 a$ and $c$ ). $P$. aegeria shows much more marked niche differences between the sexes: males defend territories in patches of sunlight or patrol for mates in the canopy (Davies, 1978), whereas females spend most of their time amongst the undergrowth (personal observation); yet this species exhibits no sex differences in spotting.

Geographical variation in spotting in $P$. aegeria shows a significant decrease in the proportion of three upper hind wing spotted forms in the South-West Peninsula and a significant decrease in the proportion of five 
under hind wing spotted forms in Ireland. It could be that the warm winters of the extreme south-west do not confer such an advantage on the earlier pupation of those larvae which produce three spot adults. But both phenomena could be the result of edge of range effects. At the extreme edges of their geographic distributions organisms will encounter very different environmental conditions than they do over the rest of their range, and as a result, are often closely adapted to one particular type of habitat. One well known example of this occurs in the ground lackey moth Malacosoma castrensis. On the salt marshes of South East England this species is at the extreme western edge of its range and here its life cycle is closely tuned to allow dispersal in this habitat. The females lay their eggs on flotsam on the shore and the salt resistant eggs get washed up somewhere else along the coast thus enabling the species to colonise new habitats (Kettlewell, in Ford, 1975). However, on mainland Europe the species is widespread, being found in diverse habitats such as heaths and woods and has no particular preference for coastal areas. There is an example of this phenomenon already known in $P$. aegeria, namely the disappearance of this species from all suitable habitats around Selby in Yorkshire, except for woods on a magnesium limestone substrate, whereas in the rest of the country the species is not thus restricted (the late Mr. S. M. Jackson, personal communication). Although Yorkshire is not the extreme edge of this species range in Great Britain it is certainly sufficiently local there for the population to be under the stresses of isolation in a similar manner to those already discussed.

In $M$. jurtina such edge of range effects are of ten accompanied by genetic adaptation resulting in spot pattern changes, and it may be that $P$. aegeria is responding in a similar manner in the South-West of England and in Ireland. It would be particularly interesting to find out if a boundary phenomenon exists in $P$. aegeria, as is the case with $M$. jurtina where the bimodal spot pattern of the "East Cornish" stabilisation meets the unimodal "Southern English" one.

Acknowledgements. I should like to thank Professor E. B. Ford for suggesting and supervising the work outlined here and for commenting on the manuscript. I am also grateful to Dr. Michael Gates for his helpful comments. Thanks are also due to Mr. Carter of the British Museum and the staff of the Hope Department of Entomology for allowing me to look at the specimens under their jurisdiction. I would also like to express my gratitude to the several amateur entomologists who have sent me data from their private collections and in particular Mr. T. W. Harman.

\section{REFERENCES}

BRAKEFIELD, P. M. (1982a). Ecological studies on the butterfly Maniola jurtina in Britain. I. Adult behaviour, microdistribution and dispersal. Journal of Animal Ecology, 51, 713-726.

BRAKEFIELD, P. M. (1982b). Ecological studies on the butterfly Maniola jurtina in Britain. II. Population dynamics: the present position. Journal of Animal Ecology, 51, 727-738. BRAKEFIELD, P. M. $(1982 c)$. The ecological genetics of quantitative characters in Maniola jurtina and other butterflies. Symposia of the Royal Entomological Society, 11, The Biology of Butterflies, (in press).

BRADSHAW. W. E. (1973). Homeostasis and polymorphism in vernal development of Chaoborus americanus. Ecology, 54, 1247-1259.

DAVIES, N. B. (1978). Territorial Defence in the Speckled Wood butterfly (Pararge aegeria): the resident always wins. Animal Behaviour, 26, 138-147. 
DOWDESWELL, W. H. (1961). Experimental studies on natural selection in the butterfly Maniola jurtina. Heredity, 16, 39-52.

FORD, E. B. (1962). Butterflies. 1st edn. Collins. London.

FORD, E. B. (1975). Ecological Genetics. 3rd edn. Chapman and Hall.

GODDARD, M. J. (1962). Broods of the Speckled Wood (Pararge aegeria aegerides Stgr) (Lep. Satyridae). Entomologist, 95, 289-307.

GODDARD, M. J. (1967). Broods of the Speckled Wood (Pararge aegeria aegerides Stgr) (Lep. Satyridae). Entomologist, 100, 241-254.

HANDFORD, P. T. (1973). Patterns of variation in a number of genetic systems in Maniola jurtina: the boundary region. Proceedings of the Royal Society of London, Series B, 183, 265-284.

Skelton, M. J. AND heAtH, J. (1975). Provisional Distribution Map of the Lepidoptera Rhopalocera. Biological Records Centre.

SUFFERT, F. (1924). Bestimmungstaktoren des Zeichnungnusters beim Saison-Dimorphismus von Araschnia levana-prorsa. Biol. Zbl., 44, 173-188.

WALDBAUer, G. P. (1978), Phenological adaptation and the polymodal emergence patterns of insects. In Dingle, H. (ed.) Evolution of Insect Migration and Diapause, Springer Verlag, Berlin, pp. 127-144.

WAldbauer, G. P. AND STernberg, J. G. (1973). Polymorphic termination of diapause by cecropia: genetic and geographical aspects. Biological Bulletin, 145, 627-641. 